\title{
Results of the second Diabetes Attitudes, Wishes and Needs (DAWN2) study: Overview of the most important results from the Polish perspective
}

\section{ABSTRACT}

Introduction. The article is a brief presentation of the most important general results of the second DAWN study conducted among patients with diabetes, families of people with diabetes and professionals involved in the treatment of diabetes in 17 countries as well as results in Poland in the context of the results obtained in other countries.

Material and methods. The study involved more than fifteen thousand participants from 17 countries. The patients and family members were contacted via the Internet, by phone or in person. Medical professionals filled questionnaires sent via Internet. Questionnaires adapted from previous DAWN studies as well as developed specifically for the purpose of this study were used to collect data. Results. The study involved 8596 adult patients with diabetes. The percentage of patients with likely depression [WHO-5 Well-Being Index (WHO-5) score $\leq 28$ ] was $14.8 \%$, with $19.2 \%$ in Poland. Diabetes-related distress [questionnaire score Problem Areas in Diabetes Scale 5 (PAID-5) $\geq 40$ ] was declared by $\mathbf{4 1 . 1 \%}$ (in Poland $56.7 \%$ ) of patients and the negative impact of the disease, in regards to their physical health, was declared by $61.2 \%$ of respondents $(72.1 \%$ in Poland).

The family members study group consisted of 2057 subjects among whom an average of $33.7 \%$ evaluated the care of the patient as a burden (in Poland $47.1 \%$ ).

Address for correspondence:

prof. dr hab. n. med. Andrzej Kokoszka

SWPS Uniwersytet Humanistycznospołeczny, Warszawa

e-mail: andrzej.kokoszka@wum.edu.pl

Translation: lek. Małgorzata Kamińska

Clinical Diabetology 2016, 5, 6, 185-194

DOI: $10.5603 /$ DK.2016.0032

Received: 15.12 .2016

Accepted: 21.02.2017
Concerns about a person with diabetes reported a significant percentage of family members, most of which, $62.1 \%$, were related to episodes of hypoglycaemia (in Poland $65.2 \%$ ). Family members declared their desire for higher involvement in the care of patients $-38.7 \%$ (in Poland, 31.6\%) as well as greater involvement in the patient's emotional problems associated with the disease, $45.6 \%$ (41.4\% in Poland).

The medical professionals study group consisted of 4785 subjects providing medical care for patients with diabetes. In most, an average of $85.4 \%$ of respondents believed that shared responsibility increases the efficiency of diabetes treatment (in Poland $86.6 \%$ ). The most important areas of self-management were: improvement in healthy eating $91.6 \%$ (in Poland $94.8 \%$ ) and increased physical activity - 93.4\% (in Poland 95.7\%). The organization of healthcare was evaluated as good on average by $27.6 \%$ respondents, but only by $8 \%$ in Poland. The need for better availability of diabetes nurse specialists was expressed by $66.3 \%$ of respondents (in Poland $76.8 \%$ ); the need of better team communication $\mathbf{- 5 7 . 6 \%}$ (in Poland $67.6 \%$ ); improved access to psychological and psychiatric consultations $59.7 \%$ (in Poland $74.7 \%$ ).

Conclusions. There were significant differences between countries observed regarding each parameter, but there was no country which results as a whole were better or worse than others. Research at the international level with the use of psychometric indicators can help identify both the obstacles and opportunities for the effective treatment of diabetes. (Clin Diabetol 2016; 5, 6: 185-194)

Key words: diabetes, care delivery, psychosocial factors, patient experience, family members, medical professionals 


\section{Introduction}

Diabetes is one of the biggest health problems in the world. According to epidemiological data, the incidence of diabetes is constantly increasing $[1,2]$. In 2013, the number of people with diabetes worldwide was 382 million and it is estimated that by 2035 this figure would increase to 592 million [2]. Serious complications of this disease are common. The key role of optimal metabolic control for prognosis is well documented. At the same time, studies show that adherence to medical recommendations by patients with diabetes is unsatisfactory $[3,4]$. Poor patient adherence to treatment translates directly into an increased risk of complications and, as a consequence, a shortened life expectancy. It is therefore crucial to identify factors that hinder optimal management of diabetes.

The Diabetes Attitudes, Wishes and Needs (DAWN) study performed in 2001 has shown the significance of psychological factors associated with diabetes [5]. The study involved 5426 people with diabetes and 3982 healthcare professionals from 13 countries, including Poland. The results obtained in all countries indicated the importance of psychological factors and psychosocial conditions for improving the outcome of treatment. Both the patients and the medical staff highlighted the diabetes-related distress experienced by the patients and the lack of optimal psychological support [6]. The study has shown that the psychological and educational needs of many diabetic patients remain unsatisfied and that there are serious deficiencies in terms of a holistic interdisciplinary approach to the management of diabetes. The conclusions drawn from the study have contributed to the development of the psychosocial support systems and educational programmes for diabetes patients in many countries. The DAWN study was cited in more than 350 scientific papers and its results and conclusions were discussed at international conferences.

The most important results for Poland are briefly presented in a handbook written by Kokoszka and Santorski [7] and well-publicized in many conference reports. These results were one of the factors that led to the emergence of the National Programme to Support People with Diabetes and the introduction of a chapter on the role of psychological factors in the 'Guidelines on the management of diabetic patients' representing the position of the Polish Diabetes Association. Summary of DAWN programme realization, after 5 years, all over the world and in Poland was presented in 2006 [8].

Ten years later, in 2011, the second Diabetes Attitudes, Wishes and Needs study (DAWN2) was conducted [9]. It included participants from 17 countries across 5 continents. The DAWN2 study was the result of cooperation between national and international organizations, including the International Diabetes Federation, the International Alliance of Patient Organizations, the Steno Diabetes Centre and Novo Nordisk, and is by far the largest global study in this kind. It should be noted that this study was not a repetition of questions from the first DAWN study (only a few questions were asked). Unlike the first study involving people with diabetes and medical professionals, the second study had a more holistic view on the problem of diabetes. It also included family members of people with diabetes.

The data from the DAWN2 study have been discussed in several publications. The most important results obtained in each group of study participants - patients [10], medical staff [11] and family members [12] - have been presented in the literature. Additionally, detailed results have been reported for Denmark [13], France [14] and the United States [15]. A review of overall study results in relation to data obtained in India is also available [16]. More detailed analyses are being prepared for publication. This paper discusses the data presented in three articles reporting the most important answers given by people with diabetes [10], their family members [12] and healthcare professionals [11], and compares the results obtained in Poland against those obtained in other countries.

\section{Material and method}

The study methodology has been described by Peyrot et al. [9]. It was conducted in: Algeria, Canada, China, Denmark, France, Germany, India, Italy, Japan, Mexico, the Netherlands, Poland, Russia, Spain, Turkey, United Kingdom and the United States. Patients with type 1 or type 2 diabetes aged $\geq 18$ years were invited to participate in the study. Family members participating in the study could be people over the age of 18 , free from diabetes, who lived in one household with a person with diabetes and were involved in diabetes care. The medical staff taking part in the study included diabetologists, endocrinologists, family physicians and internists as well as diabetes nurses and dieticians. The study involved over 15,000 participants, including 8596 patients with diabetes, 2057 family members and 4785 healthcare professionals. The group of people surveyed in each country comprised at least 900 participants, including 500 patients, 120 family members and 280 medical staff members.

Depending on the country, different methods of recruiting candidates were used: via Internet, by phone or direct contact. The method of recruiting the respondents was dictated by the specificity of the 
country and also by the desire to make the sample as representative as possible.

Different aspects of patient functioning and course of disease have been studied. The data collected included the following areas: sociodemographic data, disease data, health and quality of life, diabetes impact and burden, diabetes control, diabetes management, family and social support, medical support, education and information, workplace, community and neighbourhood/environment, attitudes and beliefs, wishes and needs, personal experiences.

In order to obtain the above data, the tools (questionnaires) used in other studies, modified versions of such questionnaires and new tools specifically developed for this study were utilized.

\section{Objectives}

The main objective of the study was to assess the factors that hinder or facilitate effective management of diabetes among people with diabetes, their family members and medical staff.

Additional objectives were [9]:

- comparison of health status indicators, quality of life (QoL), participation in programmes improving self-care and self-management in diabetes;

- assessment of the availability and extent of support offered to people with diabetes by therapeutic team, family and friends, the local community and society;

- identification of the most important factors hindering and facilitating patient-centred care for each group of study participants;

- showing the achievements, needs, preferences and directions of change in the groups of people involved in diabetes treatment and care.

The key questions for the entire study were [9]:

- finding effective tools to compare the assessed parameters in each country;

- factors determining the quality of life and psychosocial functioning of diabetic patients;

- factors that determine self-care behaviours;

- factors that determine an effective patient-centred medical care;

- factors that determine effective family support;

- access to health education in diabetes in each country;

- factors affecting the initiation/intensification of pharmacotherapy and patient adherence to recommendations;

- identifying changes that have occurred in the period between DAWN and DAWN2 studies;

- identifying what events have become turning points in coping with the disease and what changes are still expected.

\section{Results}

Patients with diabetes

The study involved 8596 adults with diabetes (1368 people with type 1 and 7228 people with type 2 diabetes) [10]. There were significant differences between the results obtained in different countries. The comparison presented below include also data from Additional Supporting Information of the online versions of discussed articles, because they contain more information. The results obtained in Poland were often among the worst ones and only in the very few categories the results were better than in other countries.

Of the total population, $14.8 \%$ were scored $\leq 28$ points in WHO-5 questionnaire, which is an indication for further clinical investigation for depressive episode. The lowest percentage was recorded in Mexico and Denmark and the highest - in Algeria, Turkey, Russia and Poland, where $19.2 \%$ of respondents reported symptoms indicative of possible depression.

In the Problem Areas in Diabetes (PAID-5) questionnaire, $41.1 \%$ of the respondents scored $\geq 40$, which indicates the presence of diabetes-related distress. The Netherlands had the lowest proportion of people with this score (20.8\%) and the highest one was in Algeria (65\%). In Poland this result was obtained by $56.7 \%$ of respondents, which is $14^{\text {th }}$ position in the world.

In the case of both WHO-5 and PAID-5, the results obtained in Poland were in the group of four least favourable results among all countries (Tab. 1).

Of all respondents, $13.4 \%$ rated overall quality of life as "poor or very poor". The lowest percentage of respondents who gave such answers was in China (8.8\%) and the highest - in Japan (24\%). In Poland, $13 \%$ responded this way.

A significant proportion of the respondents declared "slightly negative" or "very negative" effect of diabetes on all studied areas of life, including physical health $(61.2 \%)$, financial situation $(41.6 \%)$, relationships with family and friends (19.7\%), leisure activities (36.1\%), work or study (31.6\%) and emotional wellbeing $(44.8 \%)$. At the same time, it should be noted that $27.2 \%$ of the respondents declared a positive effect of diabetes on at least one of the mentioned areas. In all areas described, the percentage of respondents who declared negative impact of diabetes was higher in Poland than the global mean value, as shown in Table 2.

In all countries, a significant proportion of patients were concerned about the risk of hypoglycaemia. Of the respondents, 54.6\% "agreed" or "fully agreed" with the statement that they were very worried about the risk of hypoglycaemic events. The smallest proportion of such patients was in the Netherlands (28.7\%), the 
Table 1. Emotional well-being and distress among patients taking part in the study

\begin{tabular}{|c|c|c|c|}
\hline & $\begin{array}{l}\text { Mean in the } \\
\text { whole study } \\
\text { group }\end{array}$ & $\begin{array}{l}\text { Result } \\
\text { in Poland }\end{array}$ & $\begin{array}{l}\text { Polish position } \\
\text { as compared } \\
\text { to other countries* }\end{array}$ \\
\hline Psychological well-being according to WHO-5 & 57.1 & 50.1 & 16 \\
\hline Proportion of subjects with depression according to WHO-5 & $14.8 \%$ & $19.2 \%$ & 15 \\
\hline A level of diabetes-related distress according to PAID- 5 & 33.7 & 41.6 & 14 \\
\hline $\begin{array}{l}\text { Proportion of respondents with high diabetes-related distress according } \\
\text { to PAID-5 }\end{array}$ & $41.1 \%$ & $56.7 \%$ & 14 \\
\hline $\begin{array}{l}\text { Proportion of respondents who „agree” or "fully agree” with the notion } \\
\text { "I am very worried about the risk of hypoglycaemic events" }\end{array}$ & $54.6 \%$ & $70.2 \%$ & 15 \\
\hline $\begin{array}{l}\text { Proportion of respondents who agree with the notion "It is difficult } \\
\text { to pay for the diabetes medication" }\end{array}$ & $20.4 \%$ & $43.7 \%$ & 16 \\
\hline
\end{tabular}

*Ranking positions from 1 to $17 ; 1^{\text {st }}$ position means the best result and $17^{\text {th }}$ position means the worst result

Table 2. Negative impact of diabetes on specific life domains of diabetes patients

\begin{tabular}{lcc}
\hline $\begin{array}{l}\text { Proportion of respondents who declared "slightly negative" } \\
\text { or "very negative" impact of diabetes on following life domains: }\end{array}$ & $\begin{array}{c}\text { Mean in the } \\
\text { whole study } \\
\text { group }\end{array}$ & $\begin{array}{c}\text { Result } \\
\text { in Poland } \\
\text { as compared } \\
\text { to other countries* }\end{array}$ \\
\hline Physical health & $61.2 \%$ & $72.1 \%$ \\
Financial situation & $41.6 \%$ & $61.1 \%$ \\
Relationships with other people & $19.7 \%$ & $20.7 \%$ \\
Leisure activities & $36.1 \%$ & $39 \%$ \\
Work or studies & $31.6 \%$ & 16 \\
Emotional well-being & $44.8 \%$ & 13 \\
\hline
\end{tabular}

*Ranking positions from 1 to $17 ; 1^{\text {st }}$ position means the best result and $17^{\text {th }}$ position means the worst result

United States (33.9\%) and Denmark (36.6\%), while the largest - in Algeria (80\%). Besides Algeria, countries where the number of patients reporting such concerns were significantly higher than the mean value were Turkey (72.3\%), Poland (70.2\%) and Spain (69.8\%).

Patients were more likely to follow recommendations on medication and diet than those referring to blood sugar measurements, physical activity and foot inspections. Over the past 7 days, the average patient took medicines 6.2 times as recommended by a healthcare professional, followed a nutrition plan 4.9 times, performed physical exercises over 30 min 3.5 times, self-examined his/her feet 3.5 times, and measured blood glucose level 3.4 times. The rates of adherence to treatment and following the recommendations were significantly different across countries.

In the past 12 months, $45.4 \%$ of patients were asked by healthcare professional about nutrition, $32.8 \%$ were asked about anxiety or depression, and $52.8 \%$ had a foot exam. $\mathrm{HbA}_{1 \mathrm{c}}$ measurement was performed in $76.5 \%$ of patients. The highest proportions of patients who declared receiving this examination were in Japan (89.3\%), Denmark (87.5\%) and the United States (86.2\%), the lowest — in China (61.7\%), Algeria (64.9\%) and Turkey (65\%). In Poland, the $\mathrm{HbA}_{1 \mathrm{c}}$ measurements were performed during this time in $66.4 \%$ of the respondents, which is $13^{\text {th }}$ position in the world.

From $21.1 \%$ to $65.1 \%$ of the respondents for the notion "I was satisfied that my care was well organized" chose "most of the time" or "always" (M = 50.2\%); in Poland the proportion of respondents giving one of these answers was the lowest among all participating countries. Of the respondents, $20.4 \%$ agreed with the statement that it is difficult for them to pay for diabetes medication. This problem was least common in Great Britain and France. Poland, next to Mexico and China, was in the group where the highest percentage of respondents $(43.7 \%, 37.6 \%$ and $44.8 \%$, respectively) reported this problem.

Only $58.6 \%$ of all respondents participated in any educational programme, of which $79 \%$ considered it "somewhat" or "very" helpful. The lowest proportion of patients participating in educational programmes was in India (22.5\%) and the highest - in Canada 
(89.5\%). In Poland it was $78 \%$, which is in the group of the highest rates. Twenty nine percent of respondents did not rely on any source of education, information or support. The result was $14.3 \%$ to $44.3 \%$ depending on country. The lowest proportion was in Poland, and the highest in Japan.

Overall $82.2 \%$ of the patients reported receiving support from the family, $84.6 \%$ from medical staff, $59.9 \%$ from friends, $28.9 \%$ from other people in their community, and $24.4 \%$ from people at work or school. In Poland, the results were $86.9 \%$; $83.7 \%$; $67.5 \%$; $29.2 \%$ and $31.7 \%$, respectively.

At the same time, $17.6 \%$ experienced discrimination, intolerance or lack of community support due to diabetes. The proportion of patients experiencing such behaviours in Poland was higher and amounted to $24 \%$.

\section{Patient families}

DAWN2 is the largest study ever to include families of people with diabetes [12]. The study group consisted of 2057 people, more than half of them were spouses and almost one third were the parents of people with diabetes. Two thirds were women.

About half $(51.4 \%)$ of the respondents declared good or very good quality of life and only $8 \%$ - poor or very poor. In the group declaring low or very low quality of life, the majority of respondents came from Japan, where $16.9 \%$ of the respondents declared poor quality of life. Poland, with a score of $6.4 \%$, was below the median, as did Canada, Germany, the Netherlands, Denmark, Spain, Russia, India and China. At the same time, $54.6 \%$ of respondents in Poland considered their psychological well-being as good, as assessed by the WHO-5 questionnaire, placing our country at 14 out of 17 participating countries. In this case, the highest percentage was recorded in Mexico and the lowest in Italy.

Influence of illness on family members was assessed as significant by over one third of the total number of respondents (35.3\%), ranging from about $12 \%$ in Mexico to $60 \%$ in France. In Poland, as well as in Germany, Italy, Algeria, Turkey, China and Japan, this proportion was above the median of $34 \%$ and equalled around $45 \%$.

The effect of illness on the lives of family members is mainly seen by them as a discomfort related to worries about afflicted loved ones and to the possibility of having episodes of hypoglycaemia. In Poland, these two indicators were at a similar level (about $50 \%$ and about $65 \%$, respectively); similar data were obtained in Mexico, Italy, Russia, Algeria, Turkey, India and China. The lowest rates in these two areas were found in the Netherlands (about 15\% and about 35\%, respectively) and Denmark (about 25\% and about $33 \%$, respectively).
Influence of the disease on specific areas of family members' life was not so pronounced, with the greatest negative impact on emotional well-being, as reported by $44.6 \%$ of the respondents. The negative impact of a loved one's disease on family member's own physical health declared $26.7 \%$, on financial condition $-35.2 \%$, on social relations $-19.8 \%$, on entertainment $-31 \%$, on work or study $-22.9 \%$ and lastly on emotional relationship with a person suffering from diabetes $-19.8 \%$. Interestingly, more than one third of respondents (35.4\%) answered positively to the question concerning positive impact of diabetes on at least one life domain, and the percentage of positive answers was the highest in Polish population (56.9\%).

With regard to the involvement of families in diabetes care and support, the frustration caused by lack of knowledge in this field was declared by $37.1 \%$ of respondents. Poland was below the median, along with India, China, Italy, Germany, USA, Denmark and the Netherlands, with the smallest share of about $20 \%$. Willingness to be involved in the care process was declared by $39.4 \%$ of respondents and $45.8 \%$ of them wanted to offer their emotional support.

Less than a quarter of the surveyed family members declared participation in educational programmes and activities. Among the countries participating in the study, Poland achieved a relatively high score of about $28 \%$, lagging behind only Canada, the USA and Denmark. The representatives of Russia, Turkey and France declared the smallest percentage of families participating in educational projects. Of the respondents who participated in this type of activity as many as $72.1 \%$ assessed them as helpful.

Family members also assessed the existence of discrimination against people with diabetes in the community. Approximately one fifth of respondents $(21.5 \%)$ confirmed the occurrence of this phenomenon. Poland, along with Turkey, the Netherlands, France, Italy, India, China and Algeria, is positioned above the median. The highest percentage of people who witnessed discriminatory behaviour was reported in Algeria, where it was around $40 \%$. The fewest answers were from the USA, Denmark and Mexico.

By identifying areas for improvement, about half of the members of the patient's family indicated the need to prioritize diagnosis and treatment, and to improve the quality of care, including regular follow-up visits (52.2\% and $43 \%$, respectively).

\section{Medical staff}

The study included the medical staff of all groups dealing with patients with diabetes. Most of them were doctors, including GPs and internists. The remaining respondents were diabetes nurses and dieticians [11]. 
More than half of the healthcare professionals declared that they were inquiring patients about their emotional state. Some respondents reported lack of resources to support patients with emotional discomfort. The highest number of such reports came from Japan (30\% of respondents), the lowest - from Mexico (less than 10\%). Poland ranked just below the average for all countries, which amounted to $13 \%$, along with Germany, Canada and the Netherlands.

The vast majority of respondents (59.1-96.9\%) believe that the active role of the patient in his or her treatment increases the chances of success. At the same time, almost everyone claimed that at least half the patients needed to improve their eating habits. The data on other areas of self-care as physical activity or maintenance of the correct weight were similar.

A little over half of the respondents pointed out the need to improve monitoring of patients' glucose levels (62.3\%). A similar percentage declared the need for better coping of the patients with emotions (62.5\%).

As many as $79.7 \%$ of the respondents considered that patients did not have sufficient influence on health policy and less than one third (30.6\%) answered "yes" to the question whether healthcare is well organized for the management of chronic conditions. It draws attention that the differences between the countries in answers to this question are significant. The highest percentage of respondents confirming the good functioning of the healthcare system was observed in the Netherlands and amounted to over $60 \%$, whereas the lowest was in Poland and Russia with less than $10 \%$ of the affirmative answers. Below the median of $29.6 \%$ were USA, Mexico, Algeria, Turkey and Japan; above the median were France, Germany, Denmark, United Kingdom, Italy, Spain, India and China.

Almost half (44.8\%) of the respondents considered the healthcare remuneration system as one of the barriers. Factors that in the opinion of respondents may improve access to healthcare are the increase in the number of diabetes nurses (63.8\%), improved communication within diabetes care teams (56.1\%), and better access to psychologists and psychiatrists (58.7\%). The problem of communication was highlighted in the next question containing the statement that all diabetes care professionals should have formal training in effective communication. This thesis was confirmed by $63 \%$ of all respondents.

The highest percentage of positive responses concerned the questions about the need for early diagnosis (67.9\%), prevention of type 2 diabetes (78.8\%), prevention measures including weight loss and physical activity (69.7\%) and family involvement in care as a prerequisite for effective treatment (69.9\%).

The structured questionnaires for the assessment of chronic illnesses care (Healthcare Professional Patient Assessment of Chronic Illness Care DAWN Short Form, HCP-PACIC-DSF) and the "healthcare climate" (healthcare professional Health Care Climate DAWN Short Form, HCP-DSF) have revealed that many of the healthcare professionals are aware of the importance of patient-centred care in chronic illnesses. Respondents have confirmed that they have the ability to actively listen to and encourage patients to become involved in their treatment. However, only half of the respondents $(51.8 \%)$ ask their patients about the impact of the disease on their daily functioning.

A significant number of study participants stated that they did not have any postgraduate training in the care and treatment of patients with diabetes. On average, it was almost every fifth participant in the survey (19.6\%), but in some countries it was even one third of the respondents. Poland (12.4\%) is one of the four countries with the lowest proportion of such people (after China, Denmark and Germany). The highest number of healthcare professionals reporting lack of training was noted in Spain (36.4\%). The post-graduate training in diabetes treatment was reported by an average of $64.5 \%$ of the respondents. In Denmark, being at the first rating position, it was $88.1 \%$ and in Spain, at the last one, $31.5 \%$. In Poland (fifth position) the percentage was $70.4 \%$.

Education for effective communication and motivational strategies was available for about one third of all respondents (30.3\%) with a slightly higher proportion in Poland (34.8\%). Similar proportion of the respondents reported availability of tools for education on self-care and support (all respondents - 33.5\%, in Poland $-33.3 \%)$. In these areas, about half of the respondents reported the need for more training ( $56 \%$ and $50.1 \%$, respectively). Participation rate in training in psychological care for diabetes patients was only $18.4 \%$ (28.4\% in Poland), whereas 59.5\% (67.4\% in Poland) declared the need for such training.

Study participants also highlighted the need for more training in pharmacological $(47.0 \%)$ and nutritional treatment $(50.8 \%)$ in diabetes.

Most respondents emphasized the need for a wider range of psychological support that could be offered to patients by their diabetes care team. This statement was chosen by $62.7 \%$ of the respondents, but there were also significant differences between the countries. The lowest proportion of respondents declared such a need in Japan and the Netherlands, the highest - in Algeria, Turkey and Poland, where the percentage was over $70 \%$. 
Table 3. Areas in which the results obtained in Poland were more favourable than in other countries

\begin{tabular}{|c|c|c|c|}
\hline & $\begin{array}{l}\text { Mean in the } \\
\text { whole study } \\
\text { group }\end{array}$ & $\begin{array}{l}\text { Result } \\
\text { in Poland }\end{array}$ & $\begin{array}{l}\text { Polish position } \\
\text { as compared } \\
\text { to other countries* }\end{array}$ \\
\hline $\begin{array}{l}\text { Proportion of patients who declared participation in any educational } \\
\text { programme during last } 7 \text { year }\end{array}$ & $58.6 \%$ & $77.9 \%$ & 3 \\
\hline $\begin{array}{l}\text { Proportion of respondents who assessed the participation in } \\
\text { the programme mentioned above as helpful }\end{array}$ & $79.0 \%$ & $81.2 \%$ & 3 \\
\hline Frequency of self-measurements of blood glucose during last 7 days & 3.6 times & 4.9 times & 1 \\
\hline Frequency of foot self-inspection during last 7 days & 3.5 times & 4.2 times & 4 \\
\hline
\end{tabular}

*Ranking positions from 1 to $17 ; 1^{\text {st }}$ position means the best result and $17^{\text {th }}$ position means the worst result

Table 4. Diagnostic interventions in diabetes patients

\begin{tabular}{lccc}
\hline $\begin{array}{l}\text { Proportion of respondents in whom following diagnostic } \\
\text { intervention were performed by medical staff during } \\
\text { last } 12 \text { months: }\end{array}$ & $\begin{array}{c}\text { Mean in the } \\
\text { whole study } \\
\text { group }\end{array}$ & $\begin{array}{c}\text { Result } \\
\text { in Poland }\end{array}$ & $\begin{array}{c}\text { Polish position } \\
\text { as compared } \\
\text { to other countries* }\end{array}$ \\
\hline $\mathrm{HbA}_{1 \mathrm{c}}$ measurement & $76.5 \%$ & $66.4 \%$ & 13 \\
Foot examination & $52.8 \%$ & $41.4 \%$ & 15 \\
Were asked about anxiety or depression & $32.8 \%$ & $35 \%$ & 7 \\
Were asked about the type of food they eat & $45.4 \%$ & $57.5 \%$ & 3 \\
\hline
\end{tabular}

*Ranking positions from 1 to $17 ; 1^{\text {st }}$ position means the best result and $17^{\text {th }}$ position means the worst result

\section{Results obtained in Poland compared to other countries}

In many areas related to the well-being of patients and their feelings of being overwhelmed by the disease, the results obtained in Poland were less favourable than the average results in the world. Table 1 presents the results on mood and emotional distress that are particularly unfavourable in the Polish group of respondents and their comparison with the results in the world.

In Poland, the negative impact of diabetes on the different life domains declared by the respondents was greater than in most other countries, as shown in Table 2.

In some respects the responses of Polish patients were relatively favourable compared to other countries. The perceived support from family, friends and acquaintances and in the working environment was declared more often than in the world $-86.9 \%, 67.5 \%$ (the sixth most favourable) and $31.7 \%$ (the fifth most favourable result), respectively. Respective mean values for all respondents were $82.2 \%, 59.9 \%$ and $24.8 \%$. Table 3 shows other areas where the results obtained in Poland were significantly more favourable than in other countries. Table 4 shows the percentage of patients who reported specific behaviours of the medical staff.

In all countries, more than half of the family members assessed their emotional well-being as good. However, there are considerable differences between countries such as Mexico, Denmark and India with the highest percentage of positive ratings and countries closing the rating list, such as Poland, Algeria, Japan and Italy. On the other hand, the proportion of respondents with the lowest probability of depression based on the WHO-5 questionnaire assessment is the lowest in India, Canada and Denmark, not exceeding $10 \%$, and the highest in Japan and Italy - over 15\%. Poland, where the probability of depression among family members was rated at $11.5 \%$, is in the group of countries such as Mexico, Spain, France and China where these results are almost identical.

The respondents from Poland clearly indicated the financial situation as the area where the negative effect of diabetes on the members of their family is the strongest (Fig. 1).

According to the data, education programmes for the families of patients are offered in each of the participating countries and the attendance rate was $22.3 \%$ on average. The highest percentage of respondents declaring participation in these programmes was in Denmark (40.3\%), Canada (35.8\%) and the United States (30.9\%), the lowest — in Mexico (17.1\%), Turkey (15.2\%) and Russia (12.1\%). In Poland, $29.1 \%$ of the respondents participated in educational programmes for families. The assessment of the usefulness of the trainings was generally high, amounting to $72.1 \%$ on 


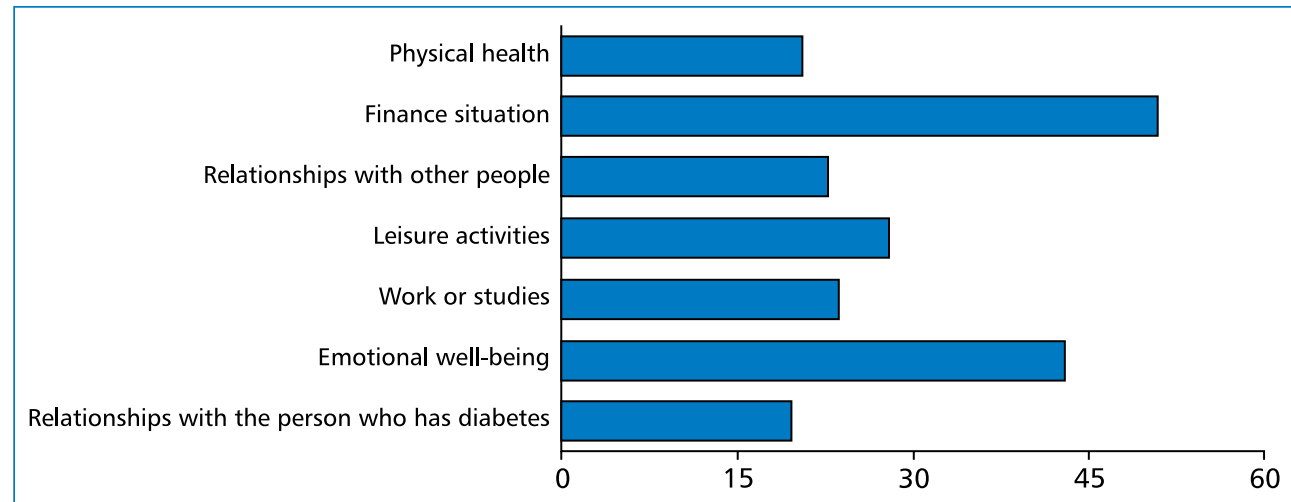

Figure 1. Declared negative impact of diabetes on specific life domains of diabetic patients' family members

average, with $73.6 \%$ of the Polish respondents satisfied with the trainings.

Assuming that the patient's psychological wellbeing is important in predicting adherence, self-control and effectiveness of therapy, it is essential to effectively identify patient with a depressed mood and implement appropriate support from caregivers. An important observation has been made by asking how many respondents from the healthcare professional group ask the patients about their well-being. Although this percentage was always above $50 \%$ and in France it exceeded $75 \%$, it is hard to resist the reflection that discussing psychological well-being is not an integral part of the overall health assessment by a healthcare provider. Poland, together with the Netherlands, Italy, Mexico, Algeria and Japan, is in the group where this proportion was around $60 \%$.

Also the percentage of staff indicating a lack of support when the interview with the patient has been assessed what suggested a psychological problem. The highest percentage was reported in Japan where almost $30 \%$ of professionals have no access to psychological referral for patients with emotional problems, while the lowest was in India and Russia - less than $10 \%$. In Poland, the results were similar as in the Netherlands, Spain, Germany and Canada where the difficulty with providing appropriate psychological support was reported by slightly over $10 \%$. It should be noted that among the respondents from Poland, only $19.6 \%$ participated in training in psychological care in diabetes and the need for such training was declared by $59.1 \%$. Based on this data, one may ask a question about awareness on the need for knowledge concerning psychological issues among the diabetes care team, which seems to be low.

Diabetes care specialists are important but not the only element of the healthcare system for the treatment of chronic diseases. The quality of the system as a whole has a clear impact on the effectiveness of the offered treatment options. Unfortunately, in Poland the proportion of professionals who favourably assess the healthcare organization is the lowest among the participating countries (Fig. 2).

\section{Discussion}

The most important limitation of the results of the DAWN2 study, as well as the first DAWN study, is the selection of the study group which is not fully representative for the surveyed countries, although the stratified representativeness was sought to be achieved. However, the postulate of ensuring representative surveyed population is extremely difficult to achieve. The results obtained should be treated with great caution, as indicating the scale of the problems and phenomena being investigated and their magnitude in the countries participating in the study.

Due to the fact that the study has been conducted via Internet and telephone, it can be concluded that the actual opinions of patients and their families are even worse. It can be expected that people who use Internet and are ready to answer questions belong to the better-functioning part of diabetic patients' population in Poland and many other countries of the world.

The results obtained in Poland show worse scores of patient well-being in comparison with other countries and a greater sense of burden of illness. Over the past 10 years since the previous DAWN study, the situation has not improved significantly. In the previous study, $60 \%$ of the respondents in Poland declared poor emotional well-being, which was third worst result among other countries, for which the average was $42 \%$.

The results of the first DAWN study were one of the inspirations for the National Programme to Support People with Diabetes and many training sessions. It can be concluded that the effects of these activities are reflected by the results, indicating that a relatively large 


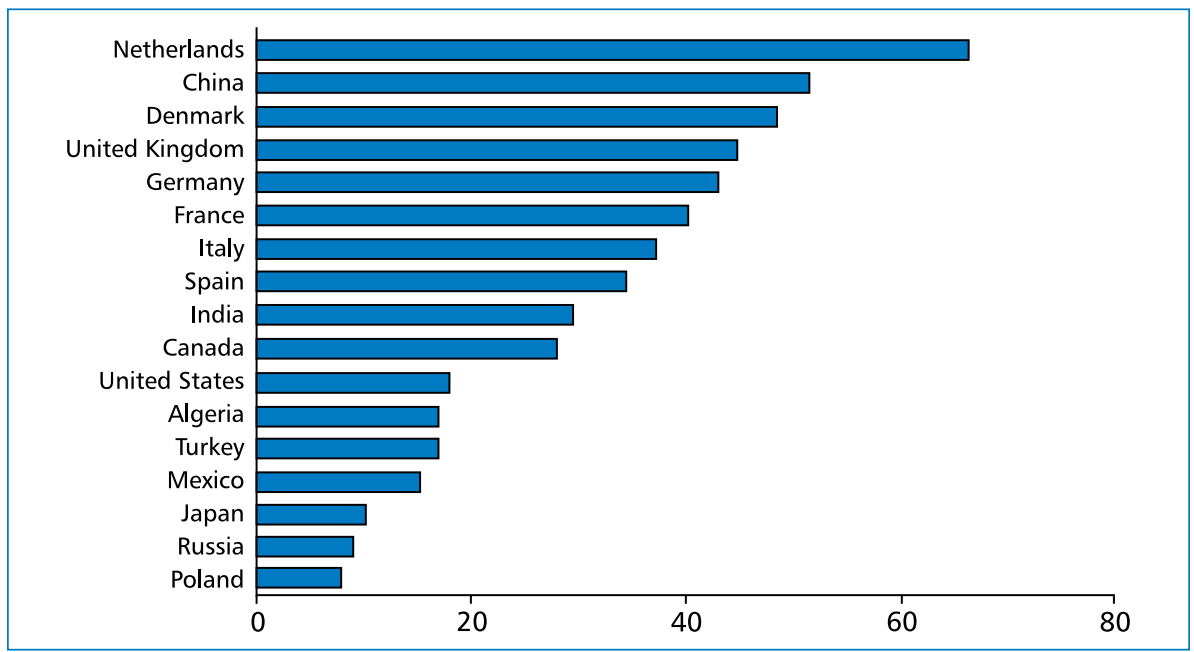

Figure 2. Proportion of healthcare professionals who positively assessed the organization of the healthcare for chronic diseases

number of people in Poland participate in educational programmes and consider them helpful. Furthermore, these educational activities may be responsible for improvement in self-management of diabetes, in particular in terms of blood glucose self-measurements and foot self-inspections, for which the results in Poland are one of the best in the world.

Medical staff in Poland is more likely to offer the patients medical procedures (blood glucose measurement and foot examination) than ask about mood or eating pattern. In the context of the reported high rates of poor psychological state and feeling significant burden of diabetes, these data indicate that a large proportion of healthcare professionals fail to follow the Guidelines on the management of diabetic patients of the Polish Diabetes Association with regard to psychological support. Improvement is still needed in this area of diabetes care. In addition, data indicating that Polish patients less frequently have their $\mathrm{HbA}_{1 \mathrm{c}}$ level measured and are considerably more frequently asked about their emotional well-being compared to other countries should be taken into account. This can be considered as the effect of the aforementioned broad educational and training activities in the medical community, which were undertaken based on the data from the first DAWN study.

Further improvement in the educational activities for family members of people with diabetes and increasing the access to psychological and social support will translate into improved care for diabetic patients.

The results of DAWN2 study indicate that further improvement in the effectiveness of diabetes treatment in Poland exceeds the range of medical capabilities. Appropriate social policy and reimbursement of treatment costs are necessary to increase treatment efficacy.
As many as $43.7 \%$ of respondents reported that they have difficulty paying for drugs, with $61.1 \%$ pointing out the negative impact of diabetes on their financial situation. Both of these results are the penultimate among other countries.

\section{Conclusions}

The results of DAWN2 study show between-country differences in opinions expressed by patients, their families and healthcare professionals considering various aspects of diabetes management. Assessing general patient care as unsatisfactory is a prevailing opinion. With regard to the individual indicators, there were significant differences between countries, but general score was similar for all participating countries. A crosscountry study using psychometric indicators could help identify both barriers and drivers in the treatment of diabetes.

Polish results indicate the relatively low well-being of people with diabetes and high conviction rate considering having adequate knowledge about this disease.

The responses of both Polish patients and their families regarding major economic problems indicate that improving diabetes management is not only a medical problem but a significant social problem. The national healthcare system for people with chronic diseases has been evaluated by Polish professionals as worst. Taking into account their accessibility to knowledge about diabetes and therapeutic treatment in this disease, the annual recommendations of the Polish Diabetes Association suggest that there is great potential for improving the effectiveness of diabetes treatment by refining the organization of healthcare in this area. 


\section{REFERENCES}

1. Jarosz-ChobotP, Otto-Buczkowska E. Epidemiologia cukrzycy typu 1. Przegl Pediatr 2009; 39: 229-234.

2. Guariguata L, Whiting DR, Hambleton I et al. Global estimates of diabetes prevalence for 2013 and projections for 2035. Diabetes Res Clin Pract 2014; 103: 137-149.

3. Kristensen JK, Bro F, Sandbaek A et al. $\mathrm{HbA}_{1 \mathrm{c}}$ in an unselected population of 4438 people with type 2 diabetes in Danish country. Scand J Prim Health Care 2001; 19: 241-246.

4. Bailey $\mathrm{CJ}$, Kodack M. Patient adherence to medication requirements for therapy of type 2 diabetes. Int J Clin Pract 2011; 65: 314-322.

5. Peyrot M, Rubin RP, Layritzen T et al. Psychosocial problems and barriers to improved diabetes management: results of the Crossnational Diabetes Attitudes, Wishes and Needs (DAWN) Study. Diabet Med 2005; 22: 1379-1385.

6. Skovlund SE, Peyrot M. The Diabetes Attitudes, Wishes and Needs (DAWN) program: a new approach to improving outcomes in diabetes care. Diabetes Spectr 2005; 18: 136-142.

7. Kokoszka A, Santorski J. Psychodiabetologia dla lekarzy: Postępowanie psychoterapeutyczne w cukrzycy. Marketing and Media, Warszawa 2003.

8. Sieradzki J, Kokoszka A, Kot W. Podsumowanie realizacji programu Diabetes, Attitudes, Wishes and Needs (DAWN) na świecie i w Polsce. Diabetol Prakt 2006; 7: 258-264.

9. Peyrot M, Burns KK, Davies $M$ et al. Diabetes Attitudes Wishes and Needs 2 (DAWN2): A multinational, multi-stakeholder study of psychosocial issues in diabetes and person-centred diabetes care. Diabetes Res Clin Pract 2013; 99: 174-184.

10. Nicolucci A, Kovacs Burns K, Escalante $M$ et al. Diabetes attitudes, wishes and needs second study (DAWN2): Cross-national benchmarking of diabetes-related psychosocial outcomes for people with diabetes. Diabet Med 2013; 30: 767-777.

11. Holt RI, Nicolucci $A$, Kovacs Burns $K$ et al. Diabetes attitudes, wishes and needs second study (DAWN2): Cross-national comparisons on barriers and resources for optimal care - healthcare professional perspective. Diabet Med 2013; 30: 789-799.

12. Kovacs Burns K, Nicolucci A, Holt RI et al. Diabetes attitudes, wishes and needs second study (DAWN2): Cross-national benchmarking indicators for family members living with people with diabetes. Diabet Med 2013; 30: 778-788.

13. Hansen UM, Jones A, Zander M, Willaing I. Denmark's comparative position regarding health status, healthcare provision, self-management and social support: Diabetes Attitudes, Wishes and Needs second study (DAWN2). Scand J Public Health 2015; 42: 111-116.

14. Reach G, Consoli SM, Halimi S et al. The multinational second Diabetes, Attitudes, Wishes and Needs study: results of the French survey. Patient Prefer Adherenca 2015; 9: 289-297.

15. Peyrot M, Egede LE, Campos $C$ et al. Ethnic differences in psychological outcomes among people with diabetes: USA results from the second Diabetes, Attitudes, Wishes, and Needs (DAWN2) study. Curr Med Res Opin 2014; 30: 2241-2254.

16. Holt RI, Kalra S. A new DAWN: Improving the psychosocial management of diabetes. Indian J Endocr Metab 2013; 17 (suppl 1): S95-S99. 